DIW BERLIN

Discussion

Papers
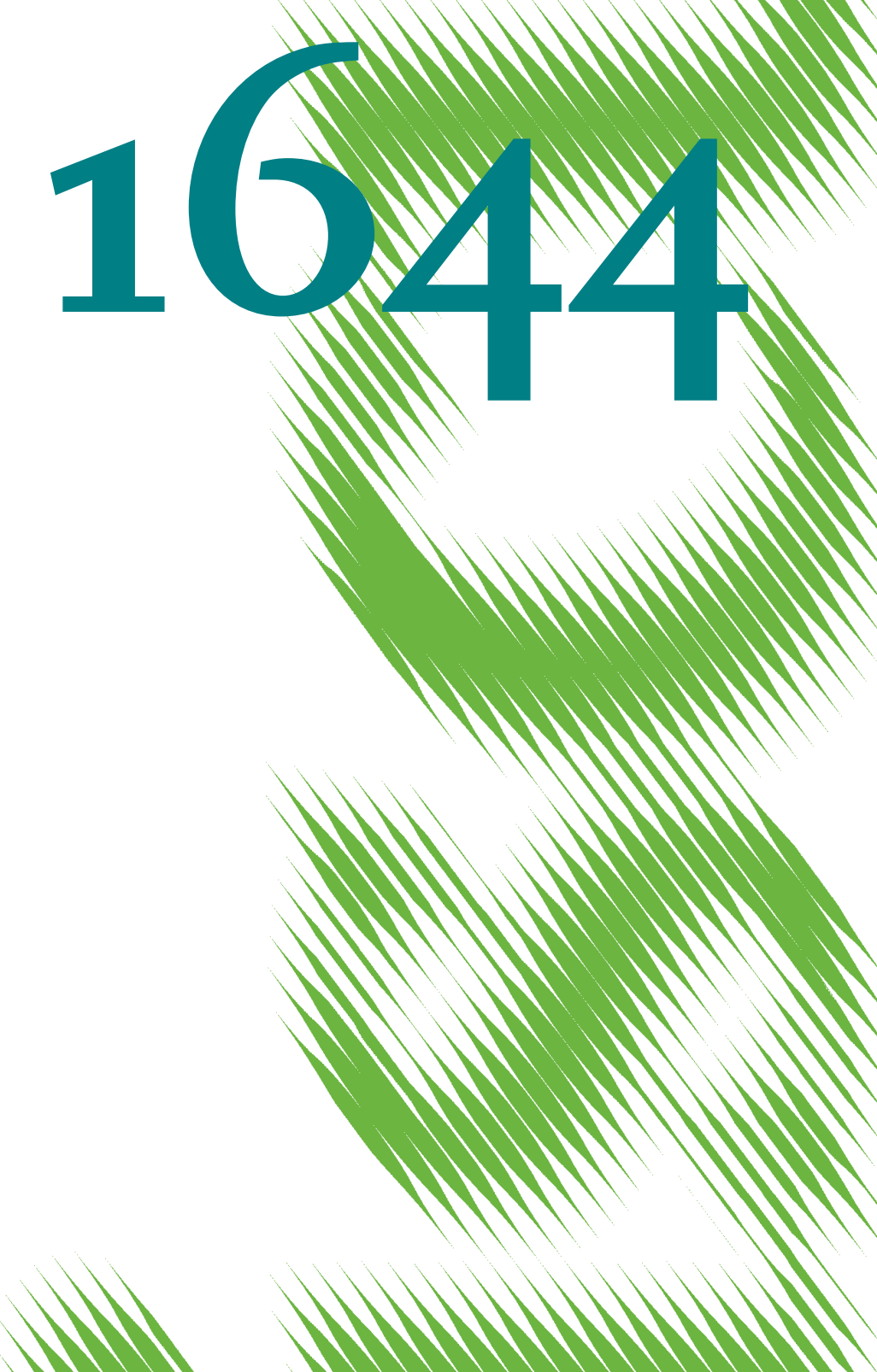

Is Socially Responsible Production a Normal Good? 
Opinions expressed in this paper are those of the author(s) and do not necessarily reflect views of the institute.

IMPRESSUM

(C) DIW Berlin, 2017

DIW Berlin

German Institute for Economic Research

Mohrenstr. 58

10117 Berlin

Tel. +49 (30) $89789-0$

Fax +49 (30) $89789-200$

http://www.diw.de

ISSN electronic edition 1619-4535

Papers can be downloaded free of charge from the DIW Berlin website:

http://www.diw.de/discussionpapers

Discussion Papers of DIW Berlin are indexed in RePEc and SSRN:

http://ideas.repec.org/s/diw/diwwpp.html

http://www.ssrn.com/link/DIW-Berlin-German-Inst-Econ-Res.html 


\title{
Is socially responsible production a normal good?*
}

\author{
Jana Friedrichsen ${ }^{\dagger}$
}

February 17, 2017

\begin{abstract}
This paper uses a controlled laboratory experiment to investigate the effect of wealth on individual social responsibility (ISR), defined as choosing a more socially responsible product if a cheaper alternative is available. We find that rich consumers are significantly less likely to engage in ISR than poor consumers. This suggests that socially responsible production conditions may not be normal product attributes.
\end{abstract}

JEL-codes: M14, A13, C91, D03

Keywords: social responsibility, consumer behavior, market experiment, wealth effect

*I am grateful to Pio Baake, Dirk Engelmann, Paola Manzini, and Helene Naegele for their feedback on earlier drafts, circulated under the title "The effect of wealth on pro-social behavior in markets". I also thank participants at the European ESA conference (Heidelberg) and EEA (Geneva), and seminar participants at DIW Berlin for their helpful comments. Iuliia Grabova and Meike Stockbrügger provided excellent research assistance. Financial support by Deutsche Forschungsgemeinschaft through SFB 649 "Economic Risk" and by the Leibniz Competition through the project GlobalFood (SAW-2015DIW-4) is gratefully acknowledged.

${ }^{\dagger}$ DIW Berlin and Humboldt-Universität zu Berlin. Mail: DIW, Mohrenstr. 58, 10117 Berlin, Germany. Phone: +49 30 89789-698. Email: jfriedrichsen@diw.de. 


\section{Introduction}

Over the last decades, Corporate Social Responsbility (CSR) and interest in it have been on the rise (The Economist, 2008). Major companies routinely report their CSR activities (KPMG, 2015), and many consumers state that they are willing to pay a premium for products that they consider ethically superior. In a representative survey in the UK in 2014, ethical standards mattered to $83 \%$ of respondents, and $38 \%$ would spend more in order to buy from an ethical firm (Ipsos MORI, 2014). Accordingly, the markets for fair trade and organic products flourish. Experimental evidence confirms that consumers positively respond to a firm's ethical conduct (e.g., Danz et al., 2012; Feicht et al., 2016, and Pigors and Rockenbach, 2016).

One argument that has been put forward to explain the rise in CSR is that social responsibility is a normal good (Bénabou and Tirole, 2010). As firms tailor their CSR activities to the consumers' demand for it in order to increase their profits (Kitzmueller and Shimshack, 2012), rising incomes should be expected to lead to rising levels of CSR. However, empirical studies of the effect of consumer income on socially responsible purchasing behavior (in the following Individual Social Reponsibility/ISR) are inconclusive, ${ }^{1}$ and they can typically not disentangle the effect of income on ISR from the effect of its correlates like education and social status.

This paper provides first evidence of a negative causal effect of income on socially responsible purchasing behavior. In a controlled laboratory experiment, where the income of the consumer is randomly determined to be either high or low, we find that rich consumers are 14 percentage points less likely to engage in ISR than poor consumers. This result suggests that preferences may change as individuals get richer, possibly outweighing positive income effects, so that ISR may not increase as incomes rise.

1 Positive income effects are, for instance, reported in Loureiro and Lotade (2005) and Andorfer (2013) but Dickson (2001) and Sunderer and Rössel (2012) among others find no effect. 


\section{Experimental design and procedures}

Participants are matched into groups of four: one consumer, one worker, and two firms. These roles are allocated randomly. Groups and roles remain fixed for the duration of the experiment. Each group plays 16 repetitions of the following market game.

Each firm $i \in 1,2$ sets a wage $w_{i}$ and a price $p_{i}$ with $w_{i}, p_{i} \in[0,40]$. The consumer learns the prices and wages of both firms, $\left(w_{1}, p_{1}\right),\left(w_{2}, p_{2}\right)$, and decides how many units to buy from each firm, $q_{1} \geq 0$ and $q_{2} \geq 0$. Each unit is worth 20 points to the consumers, and purchases can be split arbitrarily between firms as long as the total amount does not exceed 10 units. The worker has no active role but serves as a representative worker that is employed by both firms, receiving wage payments for all units sold by the two firms in their group. At the end of each period, all participants receive feedback on the prices and wages set in their group, the quantities purchased by the consumer at each firm in their group, and the payoffs of all group members.

Firms, workers, and poor consumers obtain an endowment of $e_{L}=10$ per period, and rich consumers one of $e_{H}=50$ per period. Whether a consumer is rich or poor is determined randomly at the beginning of the experiment, and is fixed for the experiment. Firms and workers know that the consumer in their group is poor or rich with equal probability but only the consumer herself learns the realization of her wealth.

Per-period payoffs are $e_{L}+\left(20-p_{1}\right) q_{1}+\left(20-p_{2}\right) q_{2}$ for poor consumers, $e_{H}+(20-$ $\left.p_{1}\right) q_{1}+\left(20-p_{2}\right) q_{2}$ for rich consumers, $e_{L}+\left(p_{i}-w_{i}\right) q_{i}$ for firm $i=1,2$, and $e_{L}+w_{1} q_{1}+w_{2} q_{2}$ for the worker. All participants are paid the sum of their earnings over all 16 periods. The exchange rate used is 1 point $=€ 0.01$.

The experiment was computerized using zTree (Fischbacher, 2007) and took place in the experimental economics laboratory at Technical University Berlin, with a total of 148 participants in 8 sessions. All participants were recruited using ORSEE (Greiner, 2015) and received identical written instructions. ${ }^{2}$ A session only started when every participant had correctly answered a set of control questions. A session lasted around 70 minutes and participants earned an average of $€ 9.96$ plus a $€ 5$ show-up fee.

\footnotetext{
${ }^{2}$ An English translation of the (German) instructions is included in the online supplement.
} 


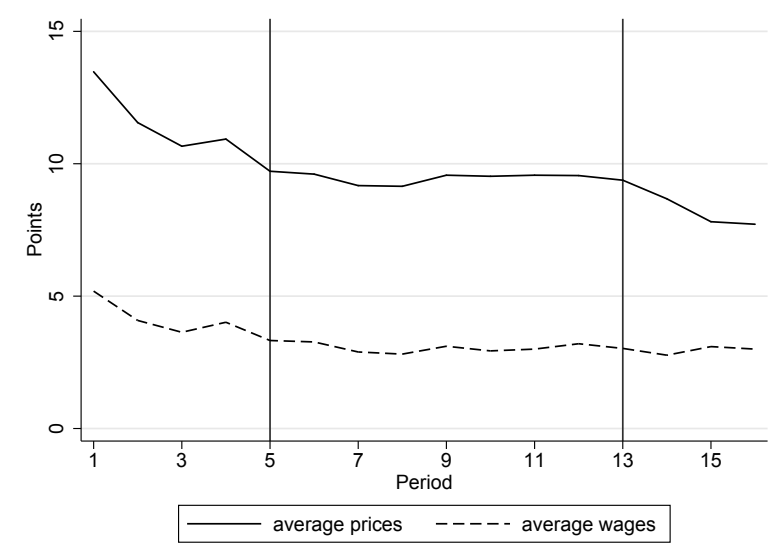

Figure 1: Posted prices and wages over time.

\section{Results}

In total, 37 groups (from now on called markets) played 16 repetitions of the market game each (592 observations). In 18 markets (288 observations) the consumer was poor, and in 19 markets (304 observations) the consumer was rich.

\subsection{Market outcomes}

Prices declined relatively quickly, then stabilized around period 5, and fell again in the very last periods (see Figure 1). Wages were more stable but also declined in the beginning. We will sometimes restrict attention to the stable phase by which we understand periods 5 to 13 . Within the stable phase, prices and wages did not exhibit any significant time trend.

Prices stabilized significantly above the subgame-perfect-Nash-equilibrium (SPNE) prediction, ${ }^{3}$ which is consistent with existing oligopoly experiments (e.g. Engel, 2007). Also wages stabilized significantly above the SPNE prediction in line with the literature (e.g. Danz et al., 2012). On average, prices exceeded wages so that both workers and firms earned positive payoffs. ${ }^{4}$ Table 1 summarizes the data.

\footnotetext{
${ }_{3}^{3}$ In this market game, the SPNE prediction is $p \in 0,1$ and $w=0$.

${ }^{4}$ Tobit regressions of prices and wages indicate that both are highly significantly different from zero $(p<0.0001)$ pooled over all 16 periods and for each individual period. Testing $p=w$ is also rejected in t-tests with $p<0.0001$.
} 


\begin{tabular}{l|ccccc|ccccc}
\hline & full sample & \multicolumn{1}{|c|}{ stable phase } \\
\hline variable & mean & SD & Min & Max & obs. & mean & SD & Min & Max & obs. \\
\hline posted price & 9.75 & 4.03 & 2 & 26.5 & 592 & 9.47 & 3.72 & 2.5 & 20 & 333 \\
posted wage & 3.33 & 2.43 & 0 & 24 & 592 & 3.06 & 1.90 & 0 & 8.5 & 333 \\
firm profit & 26.42 & 19.10 & -200 & 75 & 592 & 28.25 & 14.01 & 0 & 75 & 333 \\
consumer's payoff & 107.53 & 41.24 & -6 & 200 & 592 & 110.09 & 38.36 & 0 & 180 & 333 \\
worker's payoff & 29.06 & 28.73 & 0 & 400 & 592 & 27.34 & 18.26 & 0 & 80 & 333 \\
\hline
\end{tabular}

Table 1: Summary statistics.

Notes: Observations are group averages per period. Profits and payoffs do not include either the show-up fee or the per-period endowments. Stable phase includes periods 5 to 13.

The firms were ignorant of a consumer's wealth level, and accordingly prices and wages do not differ significantly between rich and poor groups. ${ }^{5}$

\subsection{ISR and wealth effects}

We concentrate on observations in which one of the two firms payed a strictly higher wage to the worker than its competitor but also asked a strictly higher price. We define individual social responsibility (ISR) as choosing to buy from the high-wage-high-price firm. ISR purchases increase the payoff of the worker but are costly to the consumer, who would attain the highest monetary payoff by purchasing at the cheapest price. When we restrict our sample to market situations in which one of the firms can be classified as the high-wage-high-price firm, we keep slightly more than $50 \%$ of all market situations, distributed equally between markets with rich and poor consumers (see Table 2).

Consumers typically split their purchases on both firms. ${ }^{6}$ We say a consumer's purchase decision favors ISR if she buys more units from the high-price-high-wage firm than from the competitor. Consumers favored ISR in $13.8 \%$ of all market interactions where a high-wage-high-price firm existed. As a secondary measure, we compute the share of ISR in a consumer's shopping basket by setting the number of units purchased

\footnotetext{
${ }^{5}$ The equality of the average wage in the first period in rich and poor groups cannot be rejected in a twosample t-test $(p=0.4650)$, neither can the equality of the average price in the first period be rejected $(p=0.9992)$. Differences remain insignificant if we look at periods 1 to 4 ( $p=0.3627$ for wages, $p=0.1598$ for prices) or on the full sample ( $p=0.7939$ for wages, $p=0.3594$ for prices).

${ }^{6}$ Fewer than a quarter of consumers never choose any ISR unit.
} 


\begin{tabular}{lcccccc}
\hline & \multicolumn{3}{c}{ full sample } & \multicolumn{3}{c}{ stable phase } \\
& poor & rich & overall & poor & rich & overall \\
\hline ISR possible & $51.0 \%$ & $51.6 \%$ & $51.4 \%$ & $49.4 \%$ & $52.6 \%$ & $51.1 \%$ \\
favor ISR if ISR possible & $17.7 \%$ & $10.2 \%$ & $13.8 \%$ & $21.3 \%$ & $7.8 \%$ & $14.1 \%$ \\
some ISR if ISR possible & $40.8 \%$ & $37.6 \%$ & $39.1 \%$ & $40.0 \%$ & $43.3 \%$ & $41.8 \%$ \\
share of ISR if ISR possible & $28.3 \%$ & $18.7 \%$ & $23.4 \%$ & $30.0 \%$ & $18.6 \%$ & $24.0 \%$ \\
\hline \multirow{2}{*}{ \# observations } & 288 & \multirow{2}{*}{304} & 592 & 162 & 171 & 333 \\
\hline
\end{tabular}

Table 2: Opportunity for and implementation of ISR

Notes: ISR is possible if one of the two firms is of the high-wage-high-price type.

at the high-wage-high-price firm in relation to the total quantity purchased in a period. The average share of ISR was $23 \%$.

The occurrence of ISR differed substantially with the consumer's wealth. A rich consumer was 8 percentage points less likely to favor ISR than a poor consumers. ${ }^{7}$ This difference is not driven by lack of opportunity as rich consumers had slightly more opportunities to engage in ISR (see Table 2). Also the average share of ISR was 9 percentage points lower in markets with a rich consumer than in markets with poor consumers. This difference is significant (conditioning on the existence of a highwage-high-price firm), and it is mostly driven by the difference in favor ISR as shown above. Poor and rich consumers are similarly likely to purchase a positive share not exceeding $50 \%$ of the ISR option (see some ISR in Table 2).

The differences in the raw data remain significant and the point estimates are larger than the raw differences when we control for price and wage difference in a regression analysis (Table 3). On average, a rich consumer was 14 percentage points less likely to favor ISR than a poor consumer (column 1), and the share of ISR in a consumer's shopping basket was on average 14 percentage points lower for rich consumers than for poor ones (column 2). ${ }^{8}$ ISR was also strongly influenced by price and wage differences, suggesting that consumers react to the costs $(\Delta p)$ and benefits $(\Delta w)$ of IRS.

\footnotetext{
${ }^{7}$ A rich consumer was also 10 percentage points less likely to buy at least some units from the high-pricehigh-wage firm, and she was 2 percentage points less likely to buy everything at the high-price-highwage firm.

${ }^{8}$ The results are robust to including session fixed effects, to changing the definition of the stable phase, and to dropping price and wage differences. For favor ISR, linear regressions yield even higher point estimates for rich.
} 


\begin{tabular}{lcc}
\hline Dependent: & Favor ISR & Share ISR \\
\hline & all & all \\
\hline rich & $-0.143^{* *}$ & $-0.138^{*}$ \\
& $(0.071)$ & $(0.074)$ \\
$\Delta \mathrm{p}$ & $-0.051^{* *}$ & $-0.046^{* * *}$ \\
& $(0.023)$ & $(0.015)$ \\
$\Delta \mathrm{w}$ & $0.051^{* *}$ & $0.040^{* *}$ \\
& $(0.022)$ & $(0.019)$ \\
\hline Observations & 170 & 169 \\
Wald $\chi^{2}$ & 9.46 & 14.817 \\
\hline \multicolumn{2}{c}{$p<0.10,{ }^{* *} p<0.05,^{* * *} p<0.01$}
\end{tabular}

Table 3: ISR regressed on wealth level, price and wage differences.

Notes: Column 1 reports marginal effects from logistic regression. Column 2 reports coefficients from linear regression. Both estimations include random effects and cluster-robust errors, and are restricted to markets in the stable phase where a highwage-high-price firm exists. Share ISR is not defined for one observation because no unit was purchased.

Being poor has a similar effect on the probability to favor ISR as a decrease in the price premium by 2.8 points or a same-sized increase in the wage premium of the ISR option, corresponding to a one-standard-deviation increase in the price difference or a 1.5-standard-deviation decrease in the wage difference, respectively. ${ }^{9}$ Surprisingly, the same absolute change in the price difference, affecting a consumer's own monetary payoff, and in the wage difference, affecting the worker's payoff, have the same absolute effect on a consumer's propensity toward ISR.

\section{Concluding discussion}

This paper tests whether socially responsible production is a normal good by randomly allocating wealth to consumers in a laboratory experiment. We find that consumers who were rich engaged in ISR significantly less often than poor consumers, suggesting that socially responsible production conditions are not a normal good.

The negative wealth effect appears counterintuitive at first, but the results are consistent with findings from social psychology that money primes induce participants

\footnotetext{
${ }^{9}$ The average price difference was 3 points (SD 2.57), and the average wage difference was 2.3 points (SD 1.7 ) in the sample used in the regression analysis (markets where ISR was possible during the stable phase).
} 
to focus more on their personal advantages (Vohs, 2015). In particular, individuals who are feeling privileged are more likely to become more self-serving in response to a money prime (Schuler and Wänke, 2016). In our setting, the rich consumers are those who (1) may experience money as a salient aspect because their wealth is different than that of everyone else, and who (2) are privileged in terms of wealth. In line with the psychological literature, we hypothesize that money affects rich consumers' preferences, counteracting any potentially positive income effect. With respect to the future for socially responsible production, this implies that rising incomes need not lead to further growth but consumer preferences are key.

On average, consumers in our experiment earn more than workers and or firms, and they are never budget constrained. This setting is relevant for many market settings, where socially responsible products are represented in the budget segment of large supermarkets and discounters, retail competition is fierce, and the target market for socially responsible products is a broadly defined middle class.

\section{References}

Andorfer, V. A. (2013). Ethical consumption in Germany. A cross-sectional analysis of determinants of fair trade consumption (2000-2010). Zeitschrift für Soziologie 42(5), $424-443$.

Bénabou, R. and J. Tirole (2010). Individual and corporate social responsibility. Economica 77(305), 1-19.

Danz, D., D. Engelmann, and D. Kübler (2012). Do legal standards affect ethical concerns of consumers? An experiment on minimum wages. University of Mannheim Working Paper Series, No. 12-3.

Dickson, M. A. (2001). Utility of no sweat labels for apparel consumers: Profiling label users and predicting their purchases. Journal of Consumer Affairs, 96-119.

Engel, C. (2007). How much collusion? A meta-analysis of oligopoly experiments. Journal of Competition Law and Economics 3(4), 491-549.

Feicht, R., V. Grimm, and M. Seebauer (2016). An experimental study of corporate social responsibility through charitable giving in Bertrand markets. Journal of Economic Behavior \& Organization 124, 88-101.

Fischbacher, U. (2007). Zurich toolbox for ready-made economic experiments. Experimental Economics 10(2), 171-178. 
Greiner, B. (2015). Subject pool recruitment procedures: Organizing experiments with orsee. Journal of the Economic Science Association 1(1), 114-125.

Ipsos MORI (2014). Public views on ethical retail. https://www . ipsos-mori.com/researchpublications/researcharchive/3408/ Public-views-on-ethical-retail.aspx.

Kitzmueller, M. and J. Shimshack (2012). Economic perspectives on corporate social responsibility. Journal of Economic Literature 50(1), 51-84.

KPMG (2015). The KPMG survey of corporate responsibility reporting. https://home.kpmg.com/content/dam/kpmg/pdf/2015/12/ KPMG-survey-of-CR-reporting-2015.pdf.

Loureiro, M. L. and J. Lotade (2005). Do fair trade and eco-labels in coffee wake up the consumer conscience? Ecological Economics 53(1), 129-138.

Pigors, M. and B. Rockenbach (2016). Consumer social responsibility. Management Science.

Schuler, J. and M. Wänke (2016). A fresh look on money priming: Feeling privileged or not makes a difference. Social Psychological and Personality Science 7(4), 366-373.

Sunderer, G. and J. Rössel (2012). Morality or economic interest? The impact of moral motives and economic factors on the purchase of fair trade groceries. International Journal of Consumer Studies 36(2), 244-250.

The Economist (2008). Just good business: A survey of corporate social responsibility. January 19, 2008.

Vohs, K. D. (2015). Money priming can change people's thoughts, feelings, motivations, and behaviors: An update on 10 years of experiments. Journal of Experimental Psychology: General 144(4), e86. 


\section{A Instructions}

This is a transcription of the original German instructions into English.

\section{Welcome to this experiment!}

The experiment, in which you are going to participate, helps to analyze economic decision making. You can earn money in this experiment, and the amount that you will receive at the end depends on the decisions you and the other participants make. The instructions are identical for all participants. Please read them carefully.

During the experiment you are not allowed to use electronic devices or communicate with other participants. Please only use the programs and functions provided as part of the experiment. Please do not talk to other participants. If there is anything you do not understand, please indicate this by raising your hand. We will answer your questions individually. Please do not ask your question openly. If a question is relevant for all participants, we will repeat it for everyone. If you fail to comply with these rules, we will have to exclude you from participating in the experiment and from payment.

The experiment consists of several periods with identical structure. Before the first period, each participant is randomly assigned a role, firm, worker, or consumer, that remains the same up to the end of the experiment. You know your own role but do not know the roles of other participants. Of course your anonymity will be protected throughout the entire experiment. This means that no participants will be able to trace any observed action to be the one of a specific participant.

There are two firms, one employee, and one consumers, in total four participants, in each group that remains fixed throughout the experiment. This means that the participants in the role of the firms, the worker, and the consumer with whom you interact are the same in each period.

\section{The roles}

Both firms manufacture a maximum of ten units of a homogeneous product. How much the firm actually produces depends on how many units the consumer wants to buy from the firm. The worker can be employed, also simultaneously, by both firms. A firm cannot product without employing the worker. Each firm decide about the wage that the worker earn per unit that is sold by this firm. The participant in the role of the consumer is in representative for the work force in total.

Both firms produce the same product, and both offer this product to the same consumer. The consumer can buy a maximum of ten units of the product, and can decide which firm to buy from and how many units to buy from each of them. 
All transactions are measured in points and are summarized in a savings account. At the beginning of each period, each participants earns a basic income. This income is 10 points for firms and workers. A consumers is with equal probability poor or rich. If the consumer is poor the income is also 10 points. If the consumer is rich, the income is 50 points per period. The level of income is privately know to the respective consumer. The other participants do not know whether a consumer is rich or poor.

All other payments depend on the participant's role:

- The worker receives the wage paid by the firm. It is a piece rate; that is, the worker receives a fixed amount set by the firm per unit sold. The worker himself does not take any decisions. If the consumer does not buy anything from either firm, the worker does not receive a wage, and thus receives a payment of zero.

- The firm receives the unit price for the product, multiplied by the number of units bought by the consumer, minus what the firm pays the worker. If the consumer does not buy anything from the firm, the firm does not have to pay the worker, so in total, the firm receives zero.

- The value the consumer places on one unit of the good is 20 points. He can buy a maximum of 10 units, but he can also buy less. This means that he receives 200 points minus the total price if he buys 10 units of the good. If he buys less than 10 units, he receives the number of units multiplied by 20, minus the sum of the prices that he has to pay for them. The consumer can distribute the purchase of units between the two firms as desired, and he is not forced to buy from either of the two firms. If a consumer does not buy anything, he receives no payment in that period and her savings account balance remains unchanged.

\section{Examples}

1. Firm 1 sets wage $=7$ and price $=9$. Firm 2 sets wage $=2$ and price $=18$. The consumer is rich an has an endowment of 50 points. All other participants receive an endowment of 10 points. In this case, the savings account balance increases

- for the consumer by: $20 * 8-(6 * 9+2 * 18)+50=160-90+50=120$ points,

- for firm 1 by: $6 * 9-(6 * 7)+10=22$ points,

- form firm 2 by: $18 * 2-(2 * 2)+10=42$ points, and

- for the worker by: $6 * 7+2 * 2+10=56$ points.

2. Firm 1 sets wage $=4$ and price $=18$. Firm 2 sets wage $=1$ and price $=8$. The consumer purchases 7 units at firm 1 and 3 units at firm 2 . The consumer is poor and has an endowment of 10 points. All other participants receive an endowment of 10 points. In this case, the savings account balance increases

- for the consumer by: $10 * 20-(18 * 7+3 * 8)+10=60$ points,

- for firm 1 by: $7 * 18-(7 * 4)+10=108$ points,

- form firm 2 by: $3 * 8-(3 * 1)+10=31$ points, and

- for the worker by: $7 * 4+3 * 1+10=41$ points. 


\section{Procedure}

The procedure of the experiment is as follows:

1. First, each of the two firms chooses the piece rate for the worker and the price at which it wants to sell each unit of the product. Both the piece rate and the price must lie between 0 and 40 points.

2. The consumer learns the price at which each of the firms is offering the good and what piece rate it pays its employee. On this basis, the consumer decides how many units he wants to buy from each firm.

3. The purchases are made.

4. The decisions and payments to all participants are displayed on the computer screen. In addition, each participant is informed about her income and the new balance on her savings account. These are private information.

This situation will be repeated 16 times. After each period, the period's payments will be added to the savings account. During the account all payments are accumulated in the savings account.

\section{Payment}

Your final payment will amount to the final balance of your savings account. The exchange rate for the points that you can earn throughout the experiment is 100 points $=1$ Euro. In addition, you will receive a fixed amount of 5 Euro. Any losses you make will be deducted from this amount.

If there is anything you did not understand, please let us know by raising your hand. We will then answer your questions individually. 